\title{
Strategic reliance on phonological mediation in lexical access
}

\author{
VANESSA C. MILOTA, AUDRA A. WIDAU, MONTIE R. MCMICKELL, \\ JAMES F. JUOLA, and GREG B. SIMPSON \\ University of Kansas, Lawrence, Kansas
}

\begin{abstract}
The present study investigated strategic variation in reliance on phonological mediation in visual word recognition. In Experiment 1, semantically related or unrelated word primes preceded word, pseudohomophone (e.g., trane), or nonpseudohomophone (e.g., trank) targets in a lexical decision task. Semantic priming effects were found for words, and response latencies to pseudohomophones were longer in related than in unrelated prime conditions. In Experiment 2, related or unrelated word primes preceded word or pseudohomophone targets. A relatedness effect was found for words, although it was significant at a 600 -msec prime-target stimulus onset asynchrony (SOA) and not at a 200 msec SOA. There was no relatedness effect for pseudohomophones. Experiment 3 was a replication of Experiment 2, except that pseudohomophones were replaced by nonpseudohomophonic orthographic controls. Facilitation effects for related target words were greater in Experiment 3 than in Experiment 2. The results reflect apparent variations in the expectation that a related prime reliably indicates that a target is a word. Although reliance on phonological mediation might be strategically contingent, there could be a brief time period in which phonologically mediated lexical access occurs automatically. Whether phonological information is maintained or suppressed subsequently depends on its overall usefulness for the task.
\end{abstract}

An issue of controversy in word recognition research is the extent to which skilled readers rely on phonological mediation for lexical access. Some theorists have argued that phonological information is used to access meaning in English (e.g., Lukatela, Lukatela, \& Turvey, 1993; Rubenstein, Lewis, \& Rubenstein, 1971; Van Orden, Johnston, \& Hale, 1988). Other theorists have held the opposing view-that skilled readers bypass phonological information and directly access meaning via an orthographic route (e.g., Coltheart, Davelaar, Jonasson, \& Besner, 1977; Paap, Newsome, McDonald, \& Schvaneveldt, 1982). Since studies have yielded contradictory results on this issue, more complex explanations have been proposed regarding these processes. One issue concerns the independence versus interdependence of orthographic and phonological coding mechanisms. Consistent with the assumption of independent processes, many researchers have proposed two parallel routes to the internal lexicon, a direct visual route and a phonologically mediated route (e.g., Carr \& Pollatsek, 1985; Coltheart, 1978; Patterson \& Morton, 1985; Shallice, Warrington, \& McCarthy, 1983). Other models assume a fundamentally interdependent relationship among visual, phonological, and semantic processing (McClelland \& Rumelhart, 1981; Sei-

We thank Michael J. Cortese for assistance. We thank D. B. Tracy for help in statistical analysis. We also thank Thomas A. Schreiber for explanation and use of the norms list for associative primes. Correspondence should be addressed to V. C. Milota, Department of Counseling Psychology, 116 Bailey Hall, University of Kansas, Lawrence, KS 66045-2336 (e-mail: juola@statl.cc.ukans.edu). denberg \& McClelland, 1989; Stone \& Van Orden, 1993; Van Orden \& Goldinger, 1994; Van Orden, Pennington, \& Stone, 1990). Two important issues regarding variation in coding processes are addressed in this paper: the time course for processing visual versus phonological information, and the question of automatic processing versus strategic control over coding mechanisms.

Dual-process models usually assume that direct visual access occurs more rapidly than phonologically mediated access, perhaps because phonological activation involves mapping from orthography to phonology based on spelling-to-sound correspondence rules and thus requires an extra stage of processing (Carr \& Pollatsek, 1985; Coltheart, 1978; Patterson \& Morton, 1985; Shallice et al., 1983). The time-course model of Waters and Seidenberg (1985) assumes that phonological analysis lags behind orthographic analysis. Direct access in lexical decision occurs when the visual information extracted from a stimulus letter string is sufficient for identification prior to phonological activation (see also Coltheart et al., 1977; Seidenberg \& McClelland, 1989).

In contrast to assumptions by researchers such as Coltheart et al. (1977), it has been suggested recently that phonology does play an early role in the word recognition process (see Becker, 1980; Davelaar, Coltheart, Besner, \& Jonasson, 1978; Lukatela \& Turvey, 1994; Paap et al., 1982; Peter \& Turvey, 1994; Schvaneveldt \& McDonald, 1981; Stone \& Van Orden, 1993). Support for this idea has been provided by masking studies of Perfetti and Bell (1991), which suggest that phonological information is activated within about $30 \mathrm{msec}$ for words and $35-45 \mathrm{msec}$ 
for nonwords. Subsequently, Lesch and Pollatsek (1993) have implied that phonologically mediated lexical access could occur within $50 \mathrm{msec}$, but can then be ignored in favor of direct visual access somewhere between 50 and 200 msec. Van Orden's (1987) verification model suggests that lexical entries are activated exclusively by a phonological representation, and that a subsequent orthographic verification procedure is used for word recognition. In a categorization task, for example, participants erroneously classified homophones (e.g., rows is misclassified as being a flower), whereas orthographic control words (such as robs) were not so misclassified. Likewise, Van Orden et al. (1988) found that pseudohomophones were also erroneously categorized (e.g., sute classified as belonging to the clothing category), whereas orthographically equivalent nonpseudohomophones were not miscategorized. Lukatela and Turvey (1991) and Lukatela et al. (1993) advocated Van Orden's position on phonology by demonstrating that semantic priming for homophones (towed primes frog) and pseudohomophones (table primes chare) can occur in a naming task.

Horse race models suggest that lexical access is sensitive to the relative speed of processing phonology versus the speed of orthography, and that it is simply a question of which finishes first. Other more integrative models suggest that it is not a "race" between orthography and phonology, but that evidence of lexicality or nonlexicality accumulates over time, and a decision is made when sufficient evidence supporting a specific criterion is collected. This issue of finishing times may be especially important if one assumes that phonological processing and phonologically mediated lexical access can occur automatically (Humphreys, Evett, \& Taylor, 1982; Lesch \& Pollatsek, 1993; Perfetti \& Bell, 1991; Peter \& Turvey, 1994).

Other researchers have advocated flexible coding, in which selective bias to orthographic or phonological evidence is enabled depending on the probability that such evidence is a reliable predictor of lexical identity for a stimulus letter string (e.g., Coltheart, 1978; Hawkins, Reicher, Rogers, \& Peterson, 1976; Parkin \& Ellingham, 1983; Underwood, Roberts, \& Thomason, 1988). It has been suggested by Davelaar et al. (1978) that phonological coding is optional and under strategic control of the reader, and that decisions of lexicality are therefore sometimes based on the outcome of phonemic encoding and sometimes on graphemic coding. McQuade (1981) demonstrated "pseudohomophone effects" in lexical decision (longer response latencies to pseudohomophones than to nonpseudohomophones), with a small proportion of pseudohomophones relative to nonpseudohomophones. However, when the proportion of pseudohomophones was large relative to that of nonpseudohomophones, no pseudohomophone effects were shown. Parkin and Ellingham (1983) found that response times (RTs) to pseudohomophones in lexical decision were initially longer than those for nonpseudohomophones, but this difference decreased in size across trials. Simpson and Kang (1994) showed that in native Korean speakers, naming performance for Hangul (an alphabetic script with a shallow orthography, in which printed words represent nearly direct spelling-tosound correspondences) was facilitated when $80 \%$ of the stimuli were written in Hangul and only $20 \%$ were written in Hanza (Chinese logographs with a deep orthography, in which printed characters represent morphemes). However, naming performance for Hangul was slower when $20 \%$ of the stimuli were written in Hangul and $80 \%$ were written in Hanza. This implies that Korean participants attended to phonological information when it facilitated naming performance, but they inhibited it when it was largely irrelevant. The general implication is that skilled readers have strategic control over coding mechanisms, enabling them to attend to phonological information or to disregard it selectively when it hinders overall task performance.

The present study involved the use of semantic priming in a lexical decision task. Since our pseudowords were orthographically legal and similar to real words, it would have been difficult to reject them (or render them nonlexical) on the basis of their orthography alone (see Coltheart, Curtis, Atkins, \& Haller, 1993; Coltheart et al., 1977; Gillund \& Shiffrin, 1984; Ratcliff \& McKoon, 1988; Stone $\&$ Van Orden, 1993). Stone and Van Orden have characterized visual word recognition in lexical decision as a random walk process. In order to decide whether to accept or reject a letter string as a real word, certain criteria must be met. Random responding in this case occurs when a response is made prior to meeting the criteria that determine the lexicality or nonlexicality of a stimulus letter string. Therefore, the respondent may wish to gather evidence that a stimulus is or is not a word (both according to some criterial level of orthographic, phonological, or semantic evidence). On a global level, feedback on performance as well as the various visual, phonological, or semantic properties of the stimuli used in lexical decision may set the criteria for optimizing correct responding. At a more detailed level, an individual strategy may also be developed for responding on a particular trial. If the criteria for correct responding on an individual trial are incongruent with one's global expectation, errors or longer response latencies can result. The present study investigates the extent to which skilled readers can exercise control over phonologically mediated lexical access and how this relates to many of the issues previously addressed by researchers in word recognition.

\section{EXPERIMENT 1}

The purpose of the first experiment was to investigate whether phonological codes play a role in visual word recognition, whether those codes are automatically linked to the lexicon, and whether they may operate early in the word recognition process relative to visual codes. Semantic priming effects for words, pseudohomophones, and orthographically legal nonpseudohomophones were measured in a lexical decision task. If specific processing strategies are selected, they should be task contingent. In 
a lexical decision environment, the presence of pseudohomophones should discourage the use of phonological coding, at least to the extent that such suppression is possible. However, if phonology is activated earlier than orthography and plays a key role in lexical access for the skilled reader, one would expect RTs to pseudohomophones to be longer when preceded by a related prime than by an unrelated prime. A pseudohomophone such as horce might activate a lexical node for the concept "horse" via a phonological route (e.g., Van Orden et al., 1988). According to spreading activation models of semantic priming, a prime such as colt would automatically activate lexical nodes for related concepts such as "horse" (e.g., Collins \& Loftus, 1975; McNamara, 1992). The pseudoword horce might also provide partial activation of orthographic units corresponding to horse because of the visual similarity of the pseudohomophone to its baseword counterpart (e.g., Becker, 1980).

On the one hand, summation of activation from both phonological and semantic sources might signal participants to classify horce as a word (e.g., Collins \& Loftus, 1975). On the other hand, participants might fail to find an exact orthographic match for horce, so theoretically a "no" response could be made after the participant had performed an exhaustive search of visually defined sets for horce. Words can be recognized by their various visual, phonological, and semantic features. Pseudowords that contain features of low familiarity are rejected easily, whereas pseudowords with features similar to real words require a more extended memory search before such a decision can be made. Therefore, another explanation for a potential "related pseudohomophone effect" is that a related prime such as colt would increase the familiarity of horce to a point where the familiarity value of horce would be too high to classify it as a pseudoword, yet too low to classify it as a word, resulting perhaps in delayed RTs (e.g., Atkinson \& Juola, 1973; Gillund \& Shiffrin, 1984; Ratcliff \& McKoon, 1988).

\section{Method}

Participants. Seventeen undergraduate students from the University of Kansas participated for partial credit in an introductory psychology course. There were 12 men and 5 women, ranging in age from 18 to 25 years. The participants all had normal or corrected vision and were native speakers of English. Data from 1 male participant were excluded from analysis because of an error rate exceeding $10 \%$.

Equipment. The prime words and target stimuli were displayed on an NEC 3 FGX monitor connected to an ACMA 386 microcomputer. Responses were collected by a keypress on a keyboard attached to the microcomputer. The right-hand "/" key served as a response key when the target stimulus was a word, and the left-hand
" $z$ " key served as a response key for pseudoword targets. The righthand key was labeled "word" and the left-hand key was labeled "nonword." Participants viewed the screen from a distance of approximately $86 \mathrm{~cm}$.

Materials. Both the prime and target stimuli were displayed in lowercase letters, using System 16 by Metagraphics (similar to courier), with a point size of 14 . The average visual angle for character width was $.20^{\circ}$, and that for character height was $.33^{\circ}$. The range of visual angles across word/pseudoword lengths was $.67^{\circ}-2.00^{\circ}$, with an average visual angle of $1.0^{\circ}$. Each experimental set was composed of 80 word targets, 40 pseudohomophone targets, and 40 nonpseudohomophone targets. For each type of target, half were preceded by a semantically related prime word and the other half were preceded by a semantically unrelated prime word. The stimuli were constructed from 160 prime-target pairs selected from the Nelson, McEvoy, and Schreiber (1993) norms. The selected word pairs had an average prime-target relatedness probability of .60 in a first-word association paradigm.

Prime and target pairs were rematched in order to create a semantically unrelated prime condition (see Appendix). Word targets were formed into pseudohomophones, with as few orthographic alterations from the base word as possible. Nonpseudohomophones were created from pseudohomophones by letter replacement or repositioning, while equivalent orthographic similarity to the base words was retained. A procedure was used to equate pseudohomophones and nonpseudohomophones according to their base word similarity (see Van Orden, 1987). A $t$ test was used to compare the graphic similarity of each pseudohomophone to its base word (i.e., horce to horse) with the graphic similarity of each nonpseudohomophone to its base word (i.e., horte to horse). The $t$ test was nonsignificant, which implies that the pseudohomophones and the nonpseudohomophones were equated for base word similarity. Words, pseudohomophones, and nonpseudohomophones were matched for bigram frequency according to Solso and Juel's (1980) statistics. Table 1 shows the means and standard deviations for the bigram frequencies for the three target types, the letter length counts for each of the three target types, and the graphic similarity of pseudowords to base words. A one-way, three-level analysis of variance (ANOVA) on target type confirmed that the bigram frequencies did not differ significantly among target types $[F(2,318)=1.29, p=.28]$. The two types of pseudowords did not differ at all in letter length. The difference in letter length between words and pseudowords was nonsignificant $[t(159)=-1.57, p=.12]$. A post hoc test for homophony was conducted on the pseudohomophones, using the same procedures as Van Orden et al. (1988). Ten independent judges pronounced each of the pseudohomophones used in Experiments 1 and 2. The results showed that $93 \%$ of the pseudohomophones were pronounced the same as their corresponding base words by at least 9 of the 10 judges.

Each target stimulus appeared in one of six conditions. For example, the target word horse appeared as horse, horce, or horte with either a related or unrelated prime word (but never both within the same list). There were no prime or target item repetitions within the same experimental set. In order to use all forms of each stimulus, four different stimulus lists were constructed in which half the items appeared as their word forms, and half were divided into their pseudohomophone or nonpseudohomophone derivatives. In this way, each item appeared twice as a word and once each as the two nonword

Table 1

Bigram Frequencies and Letter Length Counts for Target Stimuli

\begin{tabular}{lccccccc} 
& \multicolumn{3}{c}{ Words } & & \multicolumn{2}{c}{ Pseudohomophones } & \multicolumn{2}{c}{ Nonpseudohomophones } \\
\cline { 2 - 3 } & $M$ & $S D$ & & $M$ & $S D$ & $M$ & $S D$ \\
\hline Bigram frequencies & $4,457.80$ & $3,283.15$ & $4,270.66$ & 3.305 .38 & $4,085.35$ & $3,066.28$ \\
Letter length counts & 5.03 & 1.34 & 5.11 & 1.14 & 5.11 & 1.14 \\
Graphic similarity to base words & & & 713.63 & 137.53 & 702.23 & 130.61 \\
\hline
\end{tabular}


forms across lists. This procedure was repeated to yield eight different stimulus lists that were used twice each over the 16 participants in the study

Design and Procedure. Each participant was asked to perform a lexical decision task consisting of prime-target pairs from one of eight lists. There were 32 practice trials and 160 experimental trials. To start each trial, a fixation point $\left(2 \times 2 \mathrm{~mm} ; .13^{\circ} \times .13^{\circ}\right)$ appeared in the center of the screen for $500 \mathrm{msec}$ and was followed by a blank screen for $350 \mathrm{msec}$. The prime duration was $100 \mathrm{msec}$, with a prime-target stimulus onset asynchrony (SOA) of $500 \mathrm{msec}$. Thus, the interstimulus interval (ISI) was $400 \mathrm{msec}$. The target display was response terminated. The order of presentation for the prime-target pairs was random. Participants were instructed to use the prime word to aid their decision and to respond as quickly as possible, while keeping error rates to a minimum. In both the practice and experimental trials, a tone was sounded when participants responded incorrectly.

\section{Results}

The average error rate was $4.17 \%$, and there were no significant effects in the error data. Table 2 shows the means and standard deviations for correct RTs in each condition. The RT data from correct response trials were first analyzed with a two-way repeated measures ANOVA. The two independent variables were target type (words vs. pseudowords) and prime type (related vs. unrelated). The RTs for words were significantly shorter than those for pseudowords $[F(1,15)=147.26, p<.01]$. There was a target type $\times$ prime type interaction $[F(1,15)=9.1$, $p=.01]$. As anticipated (e.g., Meyer \& Schvaneveldt, 1971), RTs for words in the related condition were significantly shorter than those in the unrelated condition $[t(15)=-2.70, p=.02]$, but there were no such priming effects for pseudowords.

A separate ANOVA of the pseudoword RT data, using a two-way repeated measures design (pseudohomophones vs. nonpseudohomophones; related vs. unrelated) found significantly longer RTs for pseudohomophones than for nonpseudohomophones $[F(1,15)=6.94, p=.02]$. Pseudoword type interacted with prime type $[F(1,15)=$ $13.53, p<.01]$ in such a way that the RT difference between the related and unrelated conditions for pseudohomophones was significant $[t(15)=4.08, p<.01]$, but there was no significant relatedness effect for the nonpseudohomophones. In the related prime condition, RTs to pseudohomophones were longer than those to nonpseudohomophones $[t(15)=3.49, p<.01]$, but there was no difference between pseudohomophone and nonpseudohomophone RTs in the unrelated condition. The "pseudohomophone effect" was mainly a consequence of wordlike activation due to an interaction between semantic priming and phonological access for pseudohomophones in the related condition.

\section{Discussion}

The delayed RTs to pseudohomophones in the related prime condition are suggestive of phonologically mediated lexical access, since direct visual access would be impossible with pseudohomophones. This notion is evidenced by the fact that priming did not occur because of the visual similarity of the pseudohomophones to words, since there was no such relatedness effect shown for nonpseudohomophonic orthographic controls (see also Antos, 1979; Burgess, Tanenhaus, \& Seidenberg, 1989; Lukatela \& Turvey, 1991; Lupker, 1984; Paap et al., 1982; Rosson 1983; Schvaneveldt \& McDonald, 1981). Support was lent to the idea that pseudohomophones, like whole phonological representations, may activate a lexical node for their base word counterparts (see, e.g., Van Orden et al., 1988). If semantic priming effects occur through lexical access, the relatedness effects for pseudohomophones also reflect lexical access for pseudowords via a phonological route. The present results appear to favor phonology as a primary source of constraint on lexical access that occurs early in the word recognition process (see, e.g., Lesch \& Pollatsek, 1993; Lukatela \& Turvey, 1991; Perfetti \& Bell, 1991; Peter \& Turvey, 1994; Van Orden, 1987; Van Orden et al., 1988).

There is, however, one issue that needs further clarification. Response inhibition for pseudohomophones in the related prime condition suggests that phonological information is automatically activated, regardless of its strategic requirements (see, e.g., Henik, Friedrich, Tzelgov, \& Tramer, 1994; Humphreys et al., 1982; Lesch \& Pollatsek, 1993; Perfetti \& Bell, 1991; Peter \& Turvey, 1994), yet there was no difference between RTs to pseudohomophones and RTs to nonpseudohomophones in the unrelated condition, which implies that reliance on the phonological route is a strategic option (McQuade, 1981; Parkin \& Ellingham, 1983; Simpson \& Kang, 1994). McQuade found a pseudohomophone effect with $20 \%$ of pseudohomophonic pseudowords, but not with $80 \%$ of pseudo-

Table 2

Mean Reaction Times (in Milliseconds) and Standard Deviations for Experiment 1

\begin{tabular}{|c|c|c|c|c|c|}
\hline \multirow[b]{3}{*}{ Targets } & \multicolumn{4}{|c|}{ Primes } & \multirow{3}{*}{$\begin{array}{c}\text { Priming } \\
\text { Effect }\end{array}$} \\
\hline & \multicolumn{2}{|c|}{ Related } & \multicolumn{2}{|c|}{ Unrelated } & \\
\hline & $M$ & $S D$ & $M$ & $S D$ & \\
\hline & \multicolumn{2}{|c|}{ nurse-doctor } & \multicolumn{2}{|c|}{ win-doctor } & \\
\hline \multirow[t]{2}{*}{ Words } & 625 & 89 & 656 & 95 & +31 \\
\hline & \multicolumn{2}{|c|}{ nurse-docter } & \multicolumn{2}{|c|}{ win-docter } & \\
\hline \multirow[t]{2}{*}{ Pseudohomophones } & 761 & 97 & 723 & 89 & -38 \\
\hline & \multicolumn{2}{|c|}{ nurse-docton } & \multicolumn{2}{|c|}{ win-docton } & \\
\hline Nonpseudohomophones & 708 & 86 & 726 & 96 & +18 \\
\hline
\end{tabular}


homophonic pseudowords in lexical decision. In the present experiment, $50 \%$ of pseudowords were pseudohomophonic. Apparently the response inhibition was due to a summation of activation between semantic feedback from the related prime (through spreading activation or some other mechanism) and phonological feedback from the target. This result is consistent with the idea that although participants might have exercised some control over whether to consider phonological information as a criterion for lexicality, phonological information itself might be impossible to completely suppress up to and including lexical access. The phonological information might thus be retained until it can be disregarded in favor of other available sources of information. Perfetti and Bell suggested that automatic phonological activation occurs within approximately $30-45 \mathrm{msec}$, after which phonologically mediated lexical access may automatically occur within 50-200 msec (as suggested by Lesch \& Pollatsek, 1993). After this time period, however, phonologically mediated lexical access may be disregarded in favor of visual lexical access (see also Van Orden's, 1987, verification model). The fact that relatedness effects were found for words in Experiment 1 indicates that semantic information was used as a criterion for lexicality, thus causing some interference on individual trials with pseudohomophones. It may be inappropriate to conclude that phonological processing can be strategically controlled via suppression; rather, it may be controlled via subsequent rejection after automatic processes are already complete. This issue is investigated more closely in Experiment 2.

\section{EXPERIMENT 2}

One might conclude from the first experiment that in the normal course of reading in young adults, phonology is automatically activated and is used for lexical access. The second experiment was an attempt to determine whether phonological coding, as a contributor to lexical access, can be strategically suppressed. In Experiment 2, all pseudoword targets were pseudohomophones, so the application of grapheme-phoneme correspondence rules should produce equivalent wordlike phonological codes for all words and pseudowords. Since phonological activation should then have been rendered irrelevant for the lexical decision, participants were expected to lessen reliance on such coding and shift attention to orthographic word recognition processes alone. We wanted to ascertain whether participants could learn to disregard semantic activation via the phonological route and focus on finding exact orthographic matches for targets.

The lengthened RTs to pseudohomophones in the related condition from the first experiment were due to an interaction between phonological codes and the related contexts. Reduction of such effects would indicate that participants can strategically dampen the convergence of phonological and semantic activation, perhaps neutralizing the phonological route to lexical access. Such strate- gies, as far as the related context is concerned, might also be based on the "relatedness proportion," or the probability that a related prime serves as an indicator that a "yes" response should be made to a target (see, e.g., Neely, 1991; Neely, Keefe, \& Ross, 1989; Tweedy, Lapinski, \& Schvaneveldt, 1977).

We also varied prime-target SOAs in the second experiment ( 200 or $600 \mathrm{msec}$ ) to investigate further the issue of automatic phonological activation. A prime acting via spreading activation could facilitate semantic processing of a target, perhaps prior to visual or phonological lexical access driven from information derived from the target (see, e.g., Collins \& Loftus, 1975; McNamara, 1992). Den Heyer, Briand, and Smith (1985) and Neely (1977) suggested that strategies involving prelexical target expectancy based on a prime may not yet be operative at a 200-msec SOA (optimal for automatic spreading activation), but may be operative after about $400 \mathrm{msec}$. According to Lesch and Pollatsek (1993), phonologically mediated lexical access occurs automatically within $50 \mathrm{msec}$ but can be disregarded in favor of visual lexical access somewhere between 50 and $200 \mathrm{msec}$. Relatedness effects should differ across SOAs if one's goals are to disregard the outcome of the phonological route, use only direct visual access to ascertain whether or not a target is a word, and rule out related pseudohomophones on this basis in favor of related words. Thus, after a $200-\mathrm{msec}$ prime-target SOA and $50 \mathrm{msec}$ of target onset, it may be impossible to suppress phonologically mediated lexical access in lieu of direct access for another $150 \mathrm{msec}$ or so. Additionally, after that 150 -msec duration, semantic priming processes should cease to be automatic, and therefore relatedness effects for words should be reduced when pseudohomophones are also semantically primed in the same lexical decision task. The distinction between related words and related pseudohomophones (on the basis of direct access, as evidenced by relatedness effects for words) could perhaps be made after a $600-\mathrm{msec}$ SOA when semantic priming processes are no longer automatic. In that scenario, the participant would still contend with automatic phonological activation, but not simultaneously with automatic semantic activation. Since there would be no summation of activation from both the prime and the phonological route, related words could be distinguished from related pseudohomophones sometime after $50 \mathrm{msec}$ of target onset via direct access, resulting in greater semantic priming effects for words (but not necessarily for pseudohomophones).

If Van Orden (1987) is correct in suggesting that the phonological route to the lexicon is superior to the orthographic route in computation of semantic codes, the present experiment should produce smaller semantic priming effects for words as well as for pseudowords. If semantic priming for words remains but there is no semantic priming for pseudohomophones, support would be lent to direct visual access (see, e.g., Coltheart et al., 1977; Jared \& Seidenberg, 1991; Paap et al., 1982; Seidenberg \& McClelland, 1989). 


\section{Method}

Participants. Eighteen undergraduate students from the University of Kansas participated for partial credit in an introductory psychology course. There were 8 men and 10 women ranging in age from 18 to 22 years. Participants all had normal or corrected vision and were native speakers of English. Data from 2 male participants were excluded from analysis due to error rates exceeding $10 \%$.

Materials. The equipment was the same as that used in Experiment 1 . The same word pairs from Experiment 1 were used in Experiment 2 (see Appendix), except that 80 targets were words and 80 targets were pseudohomophones (no nonpseudohomophones were used). Eight lists were counterbalanced for target type, prime type, and SOA. For example, a target such as horse would appear as either horse or horce with a related or unrelated prime word and following a 200 - or $600-\mathrm{msec} \mathrm{SOA}$ (but never within the same list). There were no prime word repetitions within the same experimental set.

Design and Procedure. This was a replication of Experiment 1 , except that all pseudowords were pseudohomophones. There were two SOAs (200 and $600 \mathrm{msec})$. The duration of the prime was invariant $(100 \mathrm{msec})$; thus ISI was either 100 or $500 \mathrm{msec}$. The SOA was randomized within participants.

\section{Results and Discussion}

The average error rate was $4.88 \%$, and there were no significant effects in the error data. Table 3 shows the means and standard deviations for correct RTs for the different conditions. The RT data were analyzed with a three-way repeated measures ANOVA. The independent variables were target type (word or pseudohomophone), prime type (related or unrelated), and SOA (200 or $600 \mathrm{msec}$ ).

There was a significant advantage in RTs for words over pseudohomophones $[F(1,15)=63.71, p<.01]$. The main effect of prime relatedness was not significant. RTs were significantly longer at the $200-\mathrm{msec}$ SOA than at the 600 -msec SOA $[F(1,15)=5.16, p=.04]$. There were no significant interactions involving SOA.

There was a significant two-way interaction $[F(1,15)=$ $5.53, p=.03$ ], showing that the mean RT difference between pseudohomophones and words was greater in the related condition than in the unrelated condition. Subsequent $t$ tests showed that there was no significant effect of relatedness for pseudohomophones (see also Brodeur \& Lupker, 1994); thus the inhibition in RTs for pseudohomophones in the related condition found in Experiment 1 did not occur in Experiment 2. The evidence sug- gests that phonological coding is employed in lexical decision when it is beneficial to the decision process, but it can be ignored when it is detrimental (see, e.g., Hawkins et al., 1976; McQuade, 1981; Parkin \& Ellingham, 1983). In Experiment 2 it would have been detrimental to use phonological information as a decision criterion, since all of the pseudowords were pseudohomophones.

It is also true that reliance on the prime should have been detrimental to the decision process, since equal numbers of valid and invalid semantically related cues were present. The relatedness proportion, as defined by Neely et al. (1989), is the proportion of related relative to unrelated word-prime and word-target pairs. An increased relatedness proportion will increase the magnitude of semantic priming effects (see Neely et al., 1989). The relatedness proportion of $50 \%$ for words was balanced by a spurious relatedness proportion for pseudowords. From a strategic standpoint, the prime would have been considered a poor predictor of semantic identity for a target, and overall semantic priming effects for words should have been reduced (e.g., Neely, 1991; Neely et al., 1989; Tweedy et al., 1977).

Facilitation effects collapsed across SOAs for words in the related prime condition relative to the unrelated prime condition were significant $[t(15)=-2.36, p=$ .03]. Did participants in Experiment 2 attempt to disregard the phonology, the prime, or both? The answer is based on the fact that semantic priming was found for words even though it did not occur for pseudohomophones. Therefore, we conclude that participants did not attempt to ignore the prime. The fact that semantic priming continued to occur for words when the phonological codes in the stimuli were suppressed within their appropriate time course (at least as a contributor to lexical access) suggests direct access to semantic information without phonological mediation via an orthographic route. In this case it can be useful to rely on context cues, since a direct link between the visual appearance of the word and the lexicon (or an orthographic route) can still be facilitated by semantic priming. Direct visual access in this case could be useful for distinguishing related words from related pseudohomophones, thus optimizing performance. The exception to this rule may have occurred at the 200-msec SOA during an initial stage when both

Table 3

Means Reaction Times (in Milliseconds) and Standard Deviations Across Subjects for Experiment 2

\begin{tabular}{|c|c|c|c|c|c|c|}
\hline \multirow[b]{3}{*}{ Targets } & \multirow[b]{3}{*}{$\mathrm{SOA}$} & \multicolumn{4}{|c|}{ Primes } & \multirow{3}{*}{$\begin{array}{c}\text { Priming } \\
\text { Effect }\end{array}$} \\
\hline & & \multicolumn{2}{|c|}{ Related } & \multicolumn{2}{|c|}{ Unrelated } & \\
\hline & & $\vec{M}$ & $\overline{S D}$ & $\bar{M}$ & $\overline{S D}$ & \\
\hline & & nur & ctor & wil & tor & \\
\hline \multirow{3}{*}{ Words } & 200 & 689 & 112 & 696 & 84 & +7 \\
\hline & 600 & 661 & 91 & 697 & 101 & +36 \\
\hline & & nur & cter & wi & & \\
\hline \multirow[t]{2}{*}{ Pseudohomophones } & 200 & 780 & 103 & 765 & 94 & -15 \\
\hline & 600 & 754 & 97 & 751 & 111 & -3 \\
\hline
\end{tabular}

Note-SOA. stimulus onset asynchrony (in milliseconds). 
spreading activation and phonologically mediated access were automatic and occurring simultaneously.

Although there was no three-way interaction involving target type, prime type, and SOA, there was an a priori hypothesis that priming effects for words would be less at the 200-msec SOA. Subsequent protected $t$ tests showed that RTs for words were shorter in the related prime condition than in the unrelated prime condition at the 600 -msec SOA $[t(15)=-2.71, p<.01]$, but not at the $200-\mathrm{msec}$ SOA. After a $200-\mathrm{msec}$ SOA, automatic priming processes should continue to occur between 200 and $400 \mathrm{msec}$ and gradually diminish (see Neely, 1977, 1991). However, in the present experiment, $200-400 \mathrm{msec}$ after the onset of the prime (or 0-200 msec after onset of the target), automatic priming processes should have occurred simultaneously with automatic phonological processing for the target and phonological lexical access, which also would occur within $200 \mathrm{msec}$ after target onset (Lesch \& Pollatsek, 1993). These two automatic processes, which would have occurred simultaneously, may have caused delayed response latencies for related words at the $200-\mathrm{msec}$ SOA versus the $600-\mathrm{msec}$ SOA (in which the two processes would not have occurred simultaneously), but this does not appear to be the case for unrelated words (Table 3 ). Only direct visual access could be used to distinguish related words from related pseudohomophones in lexical decision, but phonological lexical access would not and should be ignored in favor of visual processes. This process might have been unnecessary if related pseudohomophones had not also been present, because the normal priming processes for words would not have been disrupted by related pseudohomophones. There did not appear to be an interference effect for related words at the $600-\mathrm{msec} \mathrm{SOA}$, where automatic priming processes would not have occurred simultaneously with phonological lexical access. The assertion, based on results from Experiment 1, that phonological processing can be controlled only after a brief duration following stimulus onset, was also supported by the outcome of Experiment 2.

The results from Experiment 2 support the notions of direct visual access and optional reliance on phonological activation affecting the decision criteria. However, there is evidence in Experiment 2, as well as Experiment 1 , that such strategies cannot completely block an initial automatic process of phonological activation, and that phonologically mediated lexical access might occur shortly after the onset of the stimulus. Thus, timing may be an issue.

\section{EXPERIMENT 3}

The purpose of the third experiment was to shed further light on the issue of control over the use of coding mechanisms in lexical access. Experiment 3 was identical to Experiment 2, except that all the pseudohomophones from the second experiment were replaced by their respective nonpseudohomophonic orthographic controls. Therefore, no routes to lexical access would be con- strained, and all routes could be used consistently for consulting the internal lexicon for the presence or absence of an entry. In contrast to Experiment 2, phonological codes served as a reliable indicator of lexical identity for a target stimulus and could be used alone to verify whether or not a target is a word. According to Tweedy et al. (1977), facilitation for words in the related prime condition should increase as a function of the proportion of related word pairs; thus there should be a greater semantic priming effect when more related word-prime and word-target pairs are used (e.g., Neely, 1991; Neely et al., 1989). Although the proportion of related word pairs in Experiment 2 is equal to that of Experiment 3, there could be a spurious relationship between word primes and pseudohomophone targets in Experiment 2 (which could counter one's perception of the relatedness proportion in Experiment 2 ). If semantically primed pseudohomophones in Experiment 2 created a spurious association based on phonological codes, there should be less priming for words in Experiment 2 than in Experiment 3.

\section{Method}

Participants. Sixteen undergraduate students from the University of Kansas participated in partial fulfillment of credit for an introductory psychology course. There were 7 men and 9 women, with ages ranging from 18 to 23 years. All were native speakers of English, and had normal or corrected vision.

Materials. The equipment was the same as that used in Experiments 1 and 2. In Experiment 3, half of the targets were words and half were nonpseudohomophones. There were no pseudohomophones. Pseudohomophones from the eight word lists used in Experiment 2 were replaced by nonpseudohomophones (see Appendix)

Design and Procedure. Experiment 3 replicated the design and procedure used in Experiment 2, except that pseudohomophones were replaced with nonpseudohomophonic orthographic controls.

\section{Results and Discussion}

There were no significant effects in the error data, and the average error rate was $2.63 \%$. Table 4 shows the means and standard deviations for correct RTs in Experiment 3 . The RT data were analyzed with a three-way repeated measures ANOVA. The independent variables were identical to those in Experiment 2, except that words were compared with nonpseudohomophones instead of pseudohomophones.

Mean RTs were shorter for words than for nonpseudohomophones $[F(1,15)=37.46, p<.01]$. Responses to targets were shorter in the related than in the unrelated condition $[F(1,15)=17.05, p<.01]$. The RTs were longer in the 200-msec SOA condition than in the 600msec SOA condition $[F(1,15)=6.44, p=.02]$, as was true in Experiment 2. There were no interactions involving SOA. The interaction between target type and prime type was marginal $[F(1,15)=3.48, p<.08]$. RTs for words were shorter in the related than in the unrelated condition $[t(15)=-3.14, p=.01]$. There were no significant priming effects for nonpseudohomophones, as was expected (e.g., Schvaneveldt \& McDonald, 1981).

In order to compare the effects in Experiment 2 with those in Experiment 3, a four-way ANOVA was conducted using the two experiments as a between-participants fac- 
Table 4

Mean Reaction Times (in Milliseconds) and Standard Deviations Across Subjects for Experiment 3

\begin{tabular}{|c|c|c|c|c|c|c|}
\hline \multirow[b]{3}{*}{ Targets } & \multirow[b]{3}{*}{ SOA } & \multicolumn{4}{|c|}{ Primes } & \multirow{3}{*}{$\begin{array}{c}\text { Priming } \\
\text { Effect }\end{array}$} \\
\hline & & \multicolumn{2}{|c|}{ Related } & \multicolumn{2}{|c|}{ Unrelated } & \\
\hline & & $M$ & $S D$ & $M$ & $S D$ & \\
\hline & & nur & ctor & wir & & \\
\hline \multirow[t]{3}{*}{ Words } & 200 & 717 & 186 & 774 & 229 & +57 \\
\hline & 600 & 703 & 185 & 765 & 217 & +62 \\
\hline & & \multicolumn{2}{|c|}{ nurse-docton } & \multicolumn{2}{|c|}{ win-docton } & \\
\hline \multirow[t]{2}{*}{ Pseudohomophones } & 200 & 865 & 218 & 871 & 202 & +6 \\
\hline & 600 & 834 & 206 & 847 & 197 & +13 \\
\hline
\end{tabular}

Note-SOA, stimulus onset asynchrony (in milliseconds).

tor (pseudohomophones vs. nonpseudohomophones as a pseudoword type), with the other three factors (target type, prime type, and SOA) being repeated measures.

There was a higher overall error rate of $4.88 \%$ in $\mathrm{Ex}$ periment 2 (pseudohomophonic pseudowords) relative to the $2.63 \%$ error rate in Experiment 3 (nonpseudohomophonic pseudowords) $[F(1,30)=6.05, p=.02]$. The error data provide evidence that the lexical decision task in Experiment 2 was more difficult than that in Experiment 3, probably because in Experiment 3 (in contrast to Experiment 2) both the phonological codes and related context cues could be relied on in the word recognition process.

RTs were significantly shorter for words than for pseudowords $[F(1,30)=82.73, p<.01]$ and following related as opposed to unrelated primes $[F(1,30)=15.22, p<$ $.01]$. There was a significant interaction showing that in both experiments the semantic priming effect was larger for words than for pseudowords $[F(1,30)=7.24, p<$ $.01]$. The main effect of SOA was significant $[F(1,30)=$ $11.60, p<.01]$.

The most interesting between-experiments effect was an experiment $\times$ relatedness interaction $[F(1,30)=7.08$, $p=.01]$, showing that the effect of relatedness was greater in Experiment 3 than in Experiment 2. The lack of constraints on lexical access in Experiment 3, in contrast to Experiment 2 (in which the phonological route was constrained), may have facilitated semantic priming effects for words. A $t$ test on the priming effect for words alone (see Tables 3 and 4) showed that the 22-msec priming effect in Experiment 2 was marginally less than the 60msec priming effect in Experiment $3[t(30)=1.81, p=$ $.08]$. This suggests that participants could exercise control over reliance on the prime, since the usefulness of the prime word as a predictor of semantic identity for the target was greater in Experiment 3 than in Experiment 2 (see also Henik et al., 1994; Neely et al., 1989; Tweedy et al., 1977). In Experiment 2, half of the related context cues were valid (in the case of semantic priming for pseudohomophones). In Experiment 3, all of the related context cues were valid, since participants were not exposed to semantically primed pseudohomophones.

\section{GENERAL DISCUSSION}

One might conclude from the present studies that direct lexical access is possible and that phonologically mediated lexical access occurs automatically for a brief period after stimulus onset, after which it can be disregarded in favor of visual processes. The results of Experiment 1 provide support for Van Orden's (1987) verification model, which implies that phonological coding occurs early in the word recognition process and may be followed by subsequent orthographic verification of the lexicality of a stimulus (see, e.g., Lukatela \& Turvey, 1991; Van Orden, 1987). Experiment 2 implies that direct visual access is possible if phonology is disregarded (see, e.g., Paap et al., 1982). The present results support the idea that phonological activation is an early constraint on lexical access in visual word recognition (see Perfetti \& Bell, 1991), in contrast to assertions by Waters and Seidenberg (1985), even when it is rendered useless for lexical decision. A comparison of the results of Experiment 2 with those of Experiment 3 provided evidence that semantic priming itself can also be a strategic process, as it is affected by the reliability of a prime as a predictor of lexical identity for a target (see, e.g., Neely et al., 1989).

Processing strategies employed in Experiment 2 appeared to involve a strategic lack of faith in phonological coding and a strategic lack of reliance on semantic extraction from a stimulus based on context cues. A phonological code indicated that a letter string was or was not a word $75 \%$ of the time in Experiment $1,0 \%$ of the time in Experiment 2, and $100 \%$ of the time in Experiment 3. Therefore, phonological information should have been relied upon in Experiments 1 and 3, but not in Experiment 2 . Flexible coding strategies and one's ability to change weight lent to phonological evidence was demonstrated in Experiment 2 (see also Simpson \& Kang, 1994). In the present study, RTs for pseudohomophones in the related prime condition relative to the unrelated prime condition increased in magnitude when nonpseudohomophones were also present. The results do not discount automatic activation of phonology in visual word recognition (e.g., Humphreys et al., 1982; Perfetti \& Bell, 
1991; Peter \& Turvey, 1994), but signify that such activation may be strategically disregarded (e.g., McQuade, 1981; Parkin \& Ellingham, 1983; Simpson \& Kang, 1994).

To what extent do the present studies support direct visual access? If phonological activation was not relied upon in Experiment 2, and the prime was used to facilitate recognition for the correct orthographic appearances of words, attention in the lexical decision process must have been entirely focused on searching for a "correct orthographic match" for a stimulus (a process that might have been less efficient if nonpseudohomophones had been present). A related prime such as colt might have caused spreading activation to related concepts like "horse" (see, e.g., Collins \& Loftus, 1975; McNamara, 1992), or colt and horse may have formed a compound cue, increasing the semantic familiarity of horse (e.g., Gillund \& Shiffrin, 1984; Ratcliff \& McKoon, 1988). A target word such as horse could access a lexical node for the concept "horse" on the basis of its orthographic recognizability. But horce could not access a lexical node unless such access occurred on a phonological basis (but in Experiment 2, such a basis was clearly ignored, at least as soon as the automatic processes ceased).

What can be concluded regarding expectations of the prime, and how did semantic activation from the prime influence the lexical decision as compared with phonological activation? Semantic priming effects occurred for words in Experiment 2, at least by the $600-\mathrm{msec}$ SOA, even though they did not occur for pseudohomophones. This suggests that direct visual access was favored over phonologically mediated access to distinguish related words from related pseudohomophones, at least as soon as any automatic phonological activation could be suppressed. Although semantic priming effects for words were smaller in Experiment 2 than in Experiment 3, this was attributed to participant expectancies (see, e.g., Neely et al., 1989). In Experiment 2, the related prime was useful in aiding the decision process only to the extent that orthographic lexical access could be differentiated from phonological lexical access, whereas in Experiment 3 the related prime was always useful in distinguishing words from pseudowords on the basis of various lexical properties.

Phonology was also shown to play an automatic and early role in processing (as suggested by Perfetti \& Bell, 1991; Peter \& Turvey, 1994), and not a later role (in contrast to Coltheart et al., 1977; Waters \& Seidenberg, 1985). However, the results are inconsistent with claims that the phonological route to lexical access is necessarily superior to the orthographic route. For example, in the Van Orden (1987) categorization studies (in which homophones such as rows were falsely placed in categories such as flower), high error rates on "homophone foils" suggest that phonology was not ignored as a contributor to lexical access. In contrast to the present study, in which an error tone was sounded, Van Orden did not provide participants with accuracy feedback. Additionally, there were no homophone foils in the practice trials. Therefore, it may be misleading to conclude from Van Orden that phonology is the primary source of constraint on lexical access in all instances, since potential task inference caused by phonological mediation may have eluded the awareness of participants. When Jared and Seidenberg (1991) replicated the Van Orden study with broader categories, they also gave participants feedback on the practice trials. Jared and Seidenberg concluded that the phonological route predominates only in the case of lower frequency words.

Lukatela et al. (1993) have also proposed that the phonological route is primary for lexical access, but their use of a naming task might have predisposed participants to attend to phonology, since they had no reason to suppress it. In fact, phonologically mediated lexical access might have been helpful for their participants, as evidenced by shorter naming times for related than for unrelated pseudohomophone targets. By contrast, in the present study, use of the phonological route was not helpful in lexical decision when pseudohomophones were used as pseudowords. Yet, under these conditions, priming effects were found for words, indicating a convergence of semantic and orthographic inputs to lexical access that remained relatively intact despite suppression of phonological coding. Our results do suggest, however, that phonological mediation may be automatic and can occur prior to direct access for about 50-200 msec (perhaps depending on the stimulus), as proposed by Lesch and Pollatsek (1993). Thereafter, it may be disregarded in favor of visual processes, if such a strategy would serve to optimize task performance.

It may be most beneficial for the reader to utilize all processing modules simultaneously, but this may not always be true in tasks such as lexical decision. According to activation-verification models, the process of activating orthographic, phonological, or semantic components is separate from any subsequent verification process in lexical identification (see, e.g., Becker, 1980; Paap et al., 1982). Such models can justify selective processing in tasks such as lexical decision because they separate activation and verification processes. The contrasting view, based on interactive activation models, is that a prime and a target can activate a set of orthographic, phonological, and semantic features shared by many words, and that earlier stages of processing can feed into later stages of processing (see, e.g., McClelland \& Rumelhart, 1981; Seidenberg \& McClelland, 1989). Activation-verification models appear to be more reflective of processes in lexical decision, whereas interactive activation models might more closely reflect pure reading processes. We conclude from the present studies that various processing modules probably do interact in the word recognition process, but only to the extent that they are useful (see also Stone \& Van Orden, 1993).

Our results have not discounted the possibility that phonology is automatically activated (see, e.g., Humphreys et al., 1982; Lesch \& Pollatsek, 1993; Perfetti \& Bell, 1991; Peter \& Turvey, 1994), but simply suggest that reliance on such activation is strategically contingent on task demands. There is also evidence that semantic priming is a partially strategic process that is based on 
the expected probability that the prime will enhance performance of target recognition in lexical decision (see, e.g., Neely et al., 1989). We conclude that phonological processing and phonologically mediated lexical access occur early in the word recognition process and may be initially automatic (in support of Davelaar et al., 1978; Hawkins et al., 1976; Humphreys et al., 1982; Lesch \& Pollatsek, 1993; Lukatela \& Turvey, 1991; Perfetti \& Bell, 1991; Peter \& Turvey, 1994; Rubenstein et al., 1971; Stone \& Van Orden, 1993; Van Orden, 1987; Van Orden \& Goldinger, 1994; Van Orden et al., 1988; Van Orden et al., 1990; but in contrast with Coltheart et al., 1993; Coltheart et al., 1977; Jared \& Seidenberg, 1991; Paap et al., 1982; Patterson \& Morton, 1985; Schvaneveldt \& McDonald, 1981; Waters \& Seidenberg, 1985). However, following automatic activation during a brief period after stimulus onset, use of phonology may be employed or abandoned, depending on the reliability of the phonological route (see Davelaar et al., 1978; McQuade, 1981; Parkin \& Ellingham, 1993; Simpson \& Kang, 1994). The extent to which such strategies are conscious or unconscious on the part of the reader remains a question to be answered by future research.

\section{REFERENCES}

Antos, S. J. (1979). Processing facilitation in a lexical decision task. Journal of Experimental Psychology: Human Perception \& Performance, 5, 527-545.

AtKinson, R. C., \& Juola, J. F. (1973). Factors influencing speed and accuracy of word recognition. In S. Kornblum (Ed.), Attention and performance $I V$ (pp. 583-612). New York: Academic Press.

BECKER, C. A. (1980). Semantic context effects in visual word recognition: An analysis of semantic strategies. Memory \& Cognition, 8 , 493-512.

Brodeur, D. A., \& Lupker, S. J. (1994). Investigating the effects of multiple primes: An analysis of theoretical mechanisms. Psychological Research, 57, 1-14.

Burgess, C., Tanenhaus, M. K., \& Seidenberg, M. S. (1989). Context and lexical access: Implications of nonword interference for lexical ambiguity resolution. Journal of Experimental Psychology: Learning, Memory, \& Cognition, 15, 620-632.

Carr, T. H., \& Pollatsek, A. (1985). Recognizing printed words: A look at current models. In D. Besner, T. G. Waller, \& E. M. MacKinnon (Eds.), Reading research: Advances in theory and practice (Vol. 5, pp. 1-82). San Diego: Academic Press.

Collins, A. M., \& Loftus, E. F. (1975). A spreading-activation theory of semantic processing. Psychological Review, 82, 407-428.

Coltheart, M. (1978). Lexical access in simple reading tasks. in G. Underwood (Ed.), Strategies of information processing (pp. 151216). New York: Academic Press.

Coltheart, M., Curtis, B., Atkins, P., \& Haller, M. (1993). Models of reading aloud: Dual-route and parallel-distributed-processing approaches. Psychological Review, 100, 589-608

Coltheart, M.. Davelaar, E., Jonasson, J. T., \& Besner, D. (1977). Access to the internal lexicon. In S. Dornic (Ed.), Attention and performance VI (pp. 535-555). Hillsdale, NJ: Erlbaum.

Davelaar, E. Coltheart, M., Besner, D., \& Jonasson, J. T. (1978) Phonological recoding and lexical access. Memory \& Cognition, 6 , $391-402$.

Den Heyer, K., Briand, K., \& Smith, L. (1985). Automatic and strategic effects in semantic priming: An examination of Becker's verification model. Memory \& Cognition, 13, 228-232.

Gillund, G., \& Shiffrin, R. M. (1984). A tetrieval model for both recognition and recall. Psychological Review, 91, 1-62.
Hawkins, H. L., Reicher, G. M., Rogers, M., \& Peterson, L. (1976). Flexible coding in word recognition. Journal of Experimental Psychology: Human Perception \& Performance, 2, 380-385.

Henik, A., Friedrich, F. J., Tzelgov, J., \& Tramer, S. (1994). Capacity demands of automatic processes in semantic priming. Memory \& Cognition, 22, 157-168.

Humphreys, G. W., EvetT, L. J., \& TAYLOR, D. E. (1982). Automatic phonological priming in visual word recognition. Memory \& Cognition, 10, 576-590.

JARED, D., \& SEIDENBERG, M. S. (1991). Does word identification proceed from spelling to sound to meaning? Journal of Experimental Psychology: General, 120, 358-394.

LesCh, M. F., \& PollatSeK, A. (1993). Automatic access of semantic information by phonological codes in visual word recognition. Journal of Experimental Psychology: Learning, Memory, \& Cognition, 19, 285-294.

Lukatela, G., Lukatela, K., \& Turvey, M. T. (1993). Further evidence for phonological constraints on visual lexical access: TOWED primes FROG. Perception \& Psychophysics, 53, 461-466.

Lukatela, G., \& Turvey, M. T. (1991). Phonological access of the lexicon: Evidence from associative priming with pseudohomophones. Journal of Experimental Psychology: Human Perception \& Performance, 17, 951-966.

Lukatela, G., \& Turvey, M. T. (1994). Visual lexical access is initially phonological: 2 . Evidence from phonological priming by homophones and pseudohomophones. Journal of Experimental Psychology, 123, 331-353.

LUPKER, S. J. (1984). Semantic priming without association: A second look. Journal of Verbal Learning \& Verbal Behavior, 23, 709-733.

MCClelland, J. L., \& RumelharT, D. E. (1981). An interactive activation model of context effects in letter perception: Part 1. An account of basic findings. Psychological Review, 88, 375-407.

McNamara, T. P. (1992). Priming and constraints it places on theories of memory and retrieval. Psychological Review, 99, 650-662.

MCQUADE, D. V. (1981). Variable reliance on phonological information in visual word recognition. Language \& Speech, 24, 99-109.

Meyer, D. E., \& SChvaneveldt, R. W. (1971). Facilitation in recognizing pairs of words: Evidence of a dependence between retrieval operations. Journal of Experimental Psychology, 90, 227-234.

NEELY, J. H. (1977). Semantic priming and retrieval from lexical memory: Roles of inhibitionless spreading activation and limitedcapacity attention. Journal of Experimental Psychology: General, 106, 226-254

NeELY, J. H. (1991). Semantic priming effects in visual word recognition: A selective review of current findings and theories. In D. Besner \& G. W. Humphreys (Eds.), Basic processes in reading: Visual word recognition (pp. 264-336). Hillsdale, NJ: Erlbaum.

Neely, J. H., Keefe, D. E., \& Ross K. L. (1989). Semantic priming in the lexical decision task: Roles of prospective prime-generated expectancies and retrospective semantic matching. Journal of Experimental Psychology: Learning, Memory, \& Cognition, 15, 10031019

Nelson, D. L., McEvoy, C. L., \& Schreiber, T. A. (1993). The University of South Florida word association, rhyme and word fragment norms. Unpublished manuscript.

PaAp, K. R, Newsome, S. L., McDonald, J. E., \& Schvaneveldt, R. W. (1982). An activation-verification model for letter and word recognition: The word superiority effect. Psychological Review, 89 , 573-594.

Parkin, A. J., \& Ellingham, R. (1983). Phonological recoding in lexical decision: The influence of pseudohomophones. Language \& Speech, 26, 81-90.

Patterson, K. E., \& Morton, J. (1985). From orthography to phonology: An attempt at an old interpretation. In K. E. Patterson, J. C. Marshall, \& M. Coltheart (Eds.), Surface dyslexia: Neuropsychological and cognitive studies of phonological reading (pp. 335-359). Hillsdale, NJ: Erlbaum.

Perfettr, C. A., \& Bell, L. (1991). Phonemic activation during the first $40 \mathrm{~ms}$ of word identification: Evidence from backward masking and priming. Journal of Memory \& Language, 30, 473-485.

Peter, M., \& Turvey, M. T. (1994). Phonological codes are early 
sources of constraint in visual semantic categorization. Perception \& Psychophysics, 55, 497-504.

RATCLifF, R., \& McKoon, G. (1988). A retrieval theory of priming in memory. Psychological Review, 95, 385-408.

Rosson, M. B. (1983). From SOFA to LOUCH: Lexical contributions to pseudoword pronunciation. Memory \& Cognition, 11, 152-160.

Rubenstein, H., Lewis, S. S., \& Rubenstein, M. A. (1971). Evidence for phonemic recoding in visual word recognition. Journal of Verbal Learning \& Verbal Behavior, 10, 645-654.

Schvaneveldt, R. W., \& MCDonald, J. E. (1981). Semantic context and the encoding of words: Evidence for two modes of stimulus analysis. Journal of Experimental Psychology: Human Perception \& Performance, 7, 673-687.

SeidenberG, M. S., \& MCClelland, J. L. (1989). A distributed, developmental model of word recognition and naming. Psychological Review, 96, 523-568.

Shallice, T., Warrington, E. K., \& McCarthy, R. (1983). Reading without semantics. Quarterly Journal of Experimental Psychology, 35A, 111-138.

Simpson, G. B., \& KANG, H. (1994). The flexible use of phonological information in word recognition in Korean. Journal of Memory \& Language, 33, 1-13.

SOLSO, R. L., \& JUEL, C. L. (1980). Instrumentation and techniques: Positional frequency and versatility of bigrams for two- through nineletter English words. Behavior Research Methods \& Instrumentation, 12, 297-343.
Stone, G. O., \& VAN Orden, G. C. (1993). Strategic control of processing in word recognition. Journal of Experimental Psychology. Human Perception \& Performance, 19, 744-774.

TWeedy, J. R., Lapinski, R. H., \& SchVanevelot, R. W. (1977). Semantic-context effects on word recognition: Influence of varying proportion of items presented in an appropriate context. Memory \& Cognition, 5, 84-89.

Underwood, G., Roberts, M., \& Thomason, H. (1988). Strategical invariance in lexical access: The reappearance of the pseudohomophone effect. Canadian Journal of Psychology, 42, 24-34.

VAN ORden, G. C. (1987). A ROWS is a ROSE: Spelling, sound, and reading. Memory \& Cognition, 15, 181-198.

VAN ORDEN, G. C., \& GOLDINGER, S. D. (1994). Interdependence of form and function in cognitive systems explains perception of printed words. Journal of Experimental Psychology: Human Perception \& Performance, 20, 1269-1291.

VAN ORDEN, G. C., Johnston, J. C., \& Hale, B. L. (1988). Word identification in reading proceeds from spelling to sound to meaning Journal of Experimental Psychology: Learning, Memory, \& Cognition, 14, 371-386.

Van Orden, G. C., Pennington, B. F., \& Stone, G. O. (1990). Word identification in reading and the promise of subsymbolic psycholinguistics. Psychological Review, 97, 488-522.

WATERS, G. S., \& SEIdENBERG, M. S. (1985). Spelling-sound effects in reading: Time-course and decision criteria. Memory \& Cognition, 13, $557-572$

APPENDIX

Prime and Target Letter String Pairs Used

\begin{tabular}{|c|c|c|c|c|c|c|c|c|c|}
\hline \multicolumn{2}{|c|}{ Prime } & \multicolumn{3}{|c|}{ Target } & \multicolumn{2}{|c|}{ Prime } & \multicolumn{3}{|c|}{ Target } \\
\hline Unrelated & Related & Word & PHP & NPHP & Unrelated & Related & Word & PHP & NPHP \\
\hline 1. win & nurse & doctor & docter & docton & 33. attempt & belly & stomach & stomack & stomash \\
\hline 2. cologne & win & lose & luze & leze & 34. beverage & attempt & try & trye & tryn \\
\hline 3. repair & cologne & perfume & purfume & perdume & 35. ballot & beverage & drink & drenk & dronk \\
\hline 4. pen & repair & fix & ficks & fiaks & 36. cat & ballot & vote & voat & vont \\
\hline 5. apology & pen & pencil & pensil & penkil & 37. beard & cat & $\operatorname{dog}$ & dawg & daeg \\
\hline 6. embrace & apology & sorry & sary & siry & 38. circus & beard & moustache & mustash & mustane \\
\hline 7. discuss & embrace & hug & hugg & huig & 39. large & circus & clown & cloun & cloin \\
\hline 8. atom & discuss & talk & tawk & tark & 40. nurse & large & small & smaul & smaol \\
\hline 9. bottom & atom & bomb & bomm & bomp & 41. envy & flight & airplane & airplain & airplarn \\
\hline 10. circle & bottom & top & tawp & talp & 42. stone & envy & jealousy & jealusy & jalousy \\
\hline 11. even & circle & square & squair & squaor & 43. reply & stone & rock & ralk & rark \\
\hline 12. blueberry & even & odd & aud & vod & 44. banjo & reply & answer & anser & anwer \\
\hline 13. lime & bull & cow & kow & zow & 45. frame & banjo & guitar & gitar & guita \\
\hline 14. ashtray & lime & lemon & lemun & lemok & 46. correct & frame & picture & pikture & pirture \\
\hline 15. unhappy & ashtray & cigarette & cigaret & carette & 47. alter & correct & wrong & rong & wron \\
\hline 16. saloon & unhappy & sad & sadd & sade & 48. thin & alter & change & chainge & charnge \\
\hline 17. zoo & saloon & bar & barr & barp & 49. black & thin & fat & fatt & fath \\
\hline 18. flunk & zoo & animal & animel & animan & 50. open & black & white & wight & wicht \\
\hline 19. belt & flunk & fail & fale & falp & 51. dime & open & close & cloze & clope \\
\hline 20. clarify & belt & pants & pance & panks & 52. jacket & dime & nickel & nickle & niclek \\
\hline 21. argue & clarify & clear & cleer & cleor & 53. man & jacket & coat & koat & joat \\
\hline 22. avenue & argue & fight & fite & fito & 54. scale & man & woman & womun & woban \\
\hline 23. bull & avenue & street & streat & strent & 55. wear & scale & weight & waight & wuight \\
\hline 24. colt & blueberry & muffin & muffen & muffir & 56. salt & wear & clothes & klothes & blothes \\
\hline 25. father & colt & horse & horce & horte & 57. precise & salt & pepper & peppur & peppek \\
\hline 26. joke & father & mother & muther & myther & 58. moist & precise & exact & exakt & exart \\
\hline 27. loose & joke & laugh & laff & lazz & 59. enter & moist & wet & whett & whemt \\
\hline 28. caffeine & loose & tight & teight & teeght & 60. clorox & enter & exit & exet & exir \\
\hline 29. son & caffeine & coffee & coffey & coffel & 61. glove & clorox & bleach & bleech & blerch \\
\hline 30. positive & son & daughter & dotter & dutter & 62. bacon & glove & hand & hanned & hanked \\
\hline 31. late & positive & negative & negetive & nesative & 63. career & bacon & eggs & aigs & oigs \\
\hline 32. belly & late & early & earlie & earlin & 64. like & career & job & jawb & jalb \\
\hline
\end{tabular}


APPENDIX (Continued)

\begin{tabular}{|c|c|c|c|c|c|c|c|c|c|}
\hline \multicolumn{2}{|c|}{ Prime } & \multicolumn{3}{|c|}{ Target } & \multicolumn{2}{|c|}{ Prime } & \multicolumn{3}{|c|}{ Target } \\
\hline Unrelated & Related & Word & PHP & NPHP & Unrelated & Related & Word & PHP & NPHP \\
\hline 65. globe & like & hate & hait & hant & 116. branch & auto & car & kar & dar \\
\hline 66. less & globe & world & werld & wyrld & 117. clock & branch & tree & trea & trex \\
\hline 67. north & less & more & moore & moork & 118. far & clock & time & tyme & tive \\
\hline 68. plasma & north & south & sowth & sonth & 119. insane & far & near & neer & neir \\
\hline 69. inside & plasma & blood & bludd & bluid & 120. lend & insane & crazy & craizy & craozy \\
\hline 70. flight & inside & outside & outcide & outlide & 121. west & cautious & careful & carefel & carefum \\
\hline 71. above & reflect & mirror & mirrur & mirrok & 122. sober & west & east & eest & erst \\
\hline 72. autumn & above & below & beloe & belom & 123. pork & sober & drunk & drunck & druink \\
\hline 73. cigar & autumn & fall & fawl & falp & 124. minor & pork & pig & pigg & pige \\
\hline 74. full & cigar & smoke & smoak & smonk & 125. film & minor & major & majur & mapor \\
\hline 75. nest & full & empty & emptie & emptis & 126. agony & film & movie & movee & movil \\
\hline 76. ballet & nest & bird & berd & birb & 127. aunt & agony & pain & pein & poin \\
\hline 77. thread & ballet & dance & danse & danke & 128. bank & aunt & uncle & unkle & ungle \\
\hline 78. tile & thread & needle & neadle & neddle & 129. bullet & bank & money & monie & monbe \\
\hline 79. sister & tile & floor & flor & loor & 130. credit & bullet & gun & gunn & gurn \\
\hline 80. reflect & sister & brother & bruther & brither & 131. gas & done & finish & finesh & finosh \\
\hline 81. cop & lend & borrow & barro & birro & 132, juice & gas & fuel & fule & felu \\
\hline 82. text & cop & police & polese & polone & 133. cent & juice & orange & orenge & orynge \\
\hline 83. rich & text & book & booke & boork & 134. forgive & cent & penny & peny & enny \\
\hline 84. knight & rich & poor & poore & poorm & 135. allergy & forgive & forget & forgit & forgat \\
\hline 85. macaroni & knight & armor & armer & armon & 136. rob & allergy & sneeze & sneaze & snaeze \\
\hline 86. error & macaroni & cheese & cheez & cheeb & 137. one & rob & steal & steele & steule \\
\hline 87. anatomy & error & mistake & mistaik & mistark & 138. jet & one & two & tue & tum \\
\hline 88. alive & mustard & ketchup & katchip & kotchip & 139. blade & jet & plane & plaine & plaune \\
\hline 89. back & alive & dead & dedd & deod & 140. arm & blade & knife & nife & knif \\
\hline 90. table & back & front & frunt & frint & 141. awake & arm & leg & legg & leig \\
\hline 91. day & table & chair & chare & charp & 142. boy & awake & asleep & asleap & asleop \\
\hline 92. glad & day & night & nite & nitz & 143. cavity & boy & girl & gerl & garl \\
\hline 93. king & glad & happy & happie & happik & 144. done & cavity & tooth & tewth & tawth \\
\hline 94. look & king & queen & quean & quern & 145 , halt & credit & card & kard & zard \\
\hline 95. weep & look & see & cee & dee & 146. last & halt & stop & stawp & stapp \\
\hline 96. sky & weep & cry & crie & crae & 147. rake & last & first & furst & filst \\
\hline 97. remain & sky & blue & bloo & blof & 148. broth & rake & leaves & leeves & leives \\
\hline 98. lumber & remain & stay & staye & staym & 149. select & broth & soup & soop & solp \\
\hline 99. funeral & lumber & wood & woud & woid & 150. pupil & select & choose & chooz & choob \\
\hline 100. dill & funeral & death & deth & dath & 151. helium & pupil & student & studunt & studert \\
\hline 101. lens & dill & pickle & pickel & piclek & 152. dilemma & helium & balloon & baloon & balloo \\
\hline 102. army & lens & glasses & glassus & glassep & 153. railroad & dilemma & problem & problum & priblem \\
\hline 103. bed & army & navy & navie & narve & 154. steeple & railroad & train & trane & trank \\
\hline 104. chill & bed & sleep & sleap & sleer & 155. clean & steeple & church & cherch & chorch \\
\hline 105. dumb & chill & cold & kold & jold & 156. false & clean & dirty & durty & dicty \\
\hline 106. harm & dumb & stupid & stupud & stapid & 157. infant & false & true & trew & trel \\
\hline 107. mud & harm & hurt & hert & hust & 158. listen & infant & baby & babie & babin \\
\hline 108. today & mud & dirt & dert & dort & 159. umbrella & listen & hear & heer & hean \\
\hline 109. seek & today & tomorrow & tomarrow & tokorrow & 160. cautious & umbrella & rain & rane & rans \\
\hline 110. princess & seek & find & fynd & fidd & Note-PHP, & doho & Ione & VPH & seu \\
\hline 111. mustard & princess & prince & prence & prunce & & & & & \\
\hline 112. flavor & anatomy & body & bodie & bodix & & & & & \\
\hline 113. suds & flavor & taste & tayst & talst & & & & & \\
\hline 114. increase & $\begin{array}{l}\text { suds } \\
\text { increa }\end{array}$ & $\begin{array}{l}\text { soap } \\
\text { dectease }\end{array}$ & sope & $\begin{array}{l}\text { sopt } \\
\text { decre }\end{array}$ & & anuscrip & eived $\mathrm{N}$ & 1996 & \\
\hline 115. auto & inc & decrease & decre & decrea & & & & 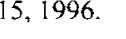 & \\
\hline
\end{tabular}

